Sección uno: Ensayo

Educación y Exclusión social

\title{
Educando en cuerpos pornográficos: Un análisis más allá de la excitación ${ }^{1}$
}

Educating in pornographic bodies: An analysis beyond excitement

Irene Rojo Soto

Universidad de Cádiz

ireneroj.so@gmail.com

\section{Resumen}

Pese a los avances logrados desde finales del siglo XX, hablar sobre la sexualidad, los cuerpos y la atracción sexual se considera todavía un tabú. La educación sexual-afectiva en España sigue estando ausente en materia de identidad y placer sexual; especialmente, hacia identidades y orientaciones sexuales periféricas. Así pues, la pornografía convencional asume el único rol educador en este campo. Además, se considera uno de los mecanismos de control de la sexualidad más importantes. Esto permite, al mismo tiempo, la eternización del poder heteronormativo, patriarcal y capitalista. Esta realidad logra perpetuar la violencia de género, la cosificación de la mujer y junto a ello, la reproducción y representación de identidades exclusivamente normativas.

Palabras claves: Pornografía, patriarcado, educación, identidad, sexualidad

\begin{abstract}
Despite the progress made since the end of the twentieth century, talking about sexuality, bodies and the sexual attraction are still considered a taboo. The sexual-affective's education in Spain is still absent in subject-matter about identity and sexual pleasure. Particularly, towards non normative sexual identities.

It is, therefore, that the mainstream porn is the only educator in this area. Moreover, it is considered one of the most important mechanism of sexuality control. It is keeping endure the heteronormativity, patriarchy and capitalism's power. This reality is spreading the gender
\end{abstract}

${ }^{1}$ Recibido: 26/07/2018 Evaluado: 10/08/2018 Aceptado: 19/09/2018 
violence and the codification of women. Besides, it is spreading the reproduction and representation solely of normative identities.

Keywords: Pornography, patriarchy, education, identity, sexualtity

\section{Introducción}

La nueva era y su transformación hacia una auto-comunicación de masas (Castells, 2009; citado por Orozco, Navarro \& García-Matilla, 2012), ha permitido abrir camino hacia una mayor consciencia feminista. Concretamente, a través de nuevas artistas que, por medio de múltiples medios de divulgación, promueven valores fundados en el feminismo y la sensibilización colectiva.

Mediante esta nueva oleada de concienciación y resignación social, sumada a los últimos acontecimientos de acoso y violación por razón de género, se consiguió que la huelga y manifestación del 8 de marzo del presente año, lograra acaparar masivamente a los medios de comunicación, con un alcance de manifestantes estimadas de 170.000 en Madrid, 200.000 en Barcelona y 100.000 en Sevilla (Anónimo, 2018).

Desde los nuevos programas de estudios académicos, y desde la educación temprana, se están ofreciendo nuevas perspectivas de género que trasgreden los estereotipos y valores impuestos por el sistema patriarcal, trabajando por una educación más equitativa. Pero bien es cierto que existen otras identidades que apenas se encuentran representadas dentro del sistema educativo, político, médico y social, viéndose sujetas tanto a estigmas y rechazo social, como a sentimientos de incomprensión y patologización.

Uno de los problemas de las nuevas identidades sexuales y su representación, es el medio de instrucción utilizado. La sexualidad se teme estar representada por la pornografía convencional la cual, por un lado, propaga actos patriarcales y machistas, y por otro, tan solo deja ver cuerpos estereotipados y normativos, con baja o nula representación de aquellos que difieran de los estipulados.

De igual modo, las formas de expresión de placer parecen ser producción, demanda y consumo exclusivamente de hombres. En cambio, a las mujeres se les niega el acceso a su propia búsqueda de placer y sexualidad, al igual que al resto de identidades que no encajan dentro del modelo masculinista hegemónico.

Además, se presupone como único medio de exploración y formación de la sexualidad, puesto que no parece tener mayor refuerzo por parte de los centros educativos. En otras palabras, las relaciones afectivo-sexuales todavía se presumen como un tema eludido en los centros primarios y secundarios, como bien afirma Cabrera (2013). 


\section{Contextualización de la pornografía}

A pesar de la frecuencia consumista que mantiene la eternización de la pornografía, resulta de gran dificultad constatar su evolución de forma exhaustiva e histórica debido, en gran parte, a las concepciones sociales, culturales y morales que se le han ido atribuyendo a lo largo de los años.

A la hora de analizar el fenómeno que acontece, aparecen cuestiones tales como: si toda sexualidad explicita es pornografía, o si el erotismo y la pornografía albergan los mismos contenidos. Las cuestiones, que en primera instancia pueden presentarse difusas, suponen una retrospección histórica para comprender la relación entre ambos términos.

Las representaciones sexuales explícitas poseen un gran recorrido histórico, siendo traducidas en objetos e iconografías que se enmarcan en el arte histórico y que, a pesar de ello, se presupone en muchos casos inconcebible en términos morales que rigen la sociedad occidental actual. Algunos ejemplos se encuentran en representaciones gráficas de felaciones en el Antiguo Egipto, copulaciones entre hombres en las cerámicas de la antigua Grecia, o imágenes donde se representan actos sexuales en el Renacimiento, las cuales contienen figuras eclesiásticas. ((Koning, 1978) \& (Montgomery, 1973); citados por Prada, 2010).

Aunque muchas películas adultas actuales puedan aparentar ser una nueva versión de lo representado históricamente, se comienzan a situar en contrariedad en la medida en la que se van analizando sus finalidades. Esto se debe, en gran parte, a que no es hasta los siglos XVIII y XIX cuando estas exhibiciones comienzan a tornar su significado, pasando de una representación que exalta críticas políticas y religiosas, hacia una finalidad únicamente de gozo y disfrute sexual (Hunt, 1993; citado en Prada, 2010).

Si bien es cierto que las imágenes sexuales explícitas comenzaron a cambiar su significado, también comienzan a modificarse las respuestas por parte de los poderes imperantes en el sistema contextual. Como bien expone Figari (2008), la estigmatización y el castigo pasaron a ser las respuestas de un sistema predominantemente religioso, las cuales no frenaron la creación de pornografía y/o imágenes eróticas, pero sí lograron convertir la pornografía en una realidad persistentemente oculta.

Tal y como expone el autor, Francia fue precursora de la continuidad de la pornografía occidental, comenzando en la mitad del siglo XIX con imágenes eróticas femeninas y pasando a daguerrotipos de representaciones sexuales explícitas y microscópicas, lo que más adelante traería consigo dos de las categorías más representadas en el porno: voyeur (mirón) y close up (observar de cerca). Un siglo más tarde, comenzarían las revistas eróticas más populares, dando inicio a las películas pornográficas convencionales a partir de los años setenta del siglo pasado.

Así pues, las manifestaciones corpóreas han estado presentes a lo largo de la historia, con dependencia causal entre las situaciones contextuales y éticas moralistas que imperaban en el espacio, y las distintas funcionalidades y formas de encarar la sexualidad explícita. 
Lo que resulta destacable es que, a medida que las finalidades menguaban y se tornaba como hechos repudiados por los grandes poderes dominantes, se fue delimitando a un ámbito más privado y discreto sin yacer en el tiempo. El objetivo de posicionar el sexo explícito en un umbral reservado ha conseguido quizá el efecto contrario con el que se veía partir, perdurando y creando nuevas formas de fantasías y deseos.

Por otra parte, las referencias tanto de pornografía como de erotismo parecen ser las mismas, lo que impide concebir de forma veraz qué era pornografía y qué era erotismo. Posiblemente esta dificultad para distinguir las disimilitudes entre ambos términos resulta aún más compleja si se extrapola lo analizado históricamente, a los hechos que concurren a fecha de hoy. Este hecho suscita un gran número de dudas, incluso desde las disciplinas feministas, impidiendo observar la fina línea divisoria que separa a ambos conceptos.

Debido a esta controversia, es recomendable partir de los orígenes etimológicos de las palabras para conocer verazmente el contenido que se encuentra no solo de forma manifiesta en la pornografía y el erotismo, si no de las ideologías latentes que se desenvuelven en ellas.

Tello (1992; citado por Llorente, 2013) expone sus orígenes como: «erotismo (gr. éroos, amor) [...] pornografía (gr. pórnee, prostituta y gráphein, escribir)» (p.361).

Ambas, enmarcadas dentro de una concepción sexual, parecen diferenciarse por el fuerte componente peyorativo que se desenvuelve dentro del término pornografía. Esta terminología muestra dos de las herramientas más poderosas que asumen los sistemas de dominación, y que tiene como denominador común la utilización de la mujer como objeto mercantil, sexual y esclavo del sistema: la pornografía convencional y la prostitución.

Asimismo, Szil (2007) expone que, a diferencia de la pornografía, las imágenes eróticas evocan una vinculación entre las personas representadas, siendo un acto que va más allá de lo que la pornografía intenta vislumbrar. Para el autor, la pornografía puede considerarse como un ejercicio meramente mercantilizado y en el cual, se busca una única relación existente: la mujer (objeto sexual representado) con el usuario (consumidor).

En primera instancia, y desde una postura conformista, se podría aceptar la diferencia asumiendo la existencia de un límite divisor. Pero entonces, se partiría de la premisa que el filme Calígula (1979) es moralmente superior a cualquier película pornográfica que representen orgías romanas, siendo ambas simbologías claras del poder androcéntrico y patriarcal con alto contenido de escenas sexuales.

Existe una complejidad no solo académica a la hora de categorizar ciertas manifestaciones sexuales, sino una dificultad cultural y moral de validar o no estas expresiones. Es por ello por lo que existe una sinonimia entre ambas terminologías junto con una especialización de los conceptos, y con el consiguiente resultado de obtener connotaciones moralmente buenas (erotismo) y malas (pornografía) (Becerra, 1989). En otras palabras, no se puede categorizar como pornográfico a fecha de hoy lo que antaño fue erótico, y viceversa.

Si se realiza una retrospección hacia el momento en el cual se evocaba la cuestión de si era «erotismo» sinónimo a «pornografía», se puede afirmar que ambos términos, conformados 
dentro de un sistema patriarcal, no son más que una etiqueta que pretende encubrir a su merced todas las prácticas de dominación machista, perpetuando la cosificación de la mujer $\mathrm{y}$ enalteciendo una femineidad instruida.

Y es que, de acuerdo con Leite (2012; citado en Barzani, 2015), lo verdaderamente trascendental es la exposición de la sexualidad como un negocio que utiliza los cuerpos como herramienta, materia y producto de consumo, con independencia de la categoría en la que se enmarque.

\section{Pornografía hegemónica: La subordinación gráfica de la mujer}

Algo que parece claro a lo largo del análisis histórico, en torno a las representaciones corpóreas como objeto de contemplación y/o excitación sexual a partir de la Europa Moderna, son los roles fuertemente marcados en base a lo que la ciencia moderna contempla como hombre o como mujer. Junto a ello, se encuentran las posiciones jerárquicas, políticas y estructurales donde se hallan establecidos, por un lado, el hombre cisgénero, heterosexual y masculinista; y por otro, la mujer cisgénero y adquisidora de una feminidad acorde con los cánones de belleza previamente establecidos por el sistema de dominio androcéntrico.

Pero si bien la pornografía enmascarada de erotismo venía aconteciendo desde siglos atrás, no es hasta los años 70 del siglo XX cuando comienzan a filmarse las primeras películas de categoría $\mathrm{X}$, abriendo paso a una gran cantidad de material pornográfico mainstream que se descubre diariamente en redes, de forma accesible y gratuita.

A pesar de continuar el análisis a través de la trayectoria filmográfica, resulta imprescindible hacer pausa en el camino para nombrar a quien para muchos abrió las puertas al nuevo Olimpo. En su traducción, será definido como el magnate que concedió a través de su imperio, los deseos sexuales más fantasiosos al hombre hegemónico y capitalista, sea cual fuere su deseo, a través de compra y venta de mujeres canónicas, estereotipadas y cosificadas.

Se trata de Hugh Hefner, el fundador y editor de la revista Playboy, y dueño de la mansión donde se lleva a cabo actuaciones y actitudes cercanas a sus publicaciones. Lanzando su primer número a principios de los años 50 del siglo XX, Hefner, desafió las leyes de censura que se venían aplicando en Norteamérica por entonces, y sin esperar repercusión alguna, terminó vendiendo 50.000 copias del primer lanzamiento, lo que le permitió proseguir con un proyecto que, en un primer momento, se estimaba incierto (Preciado, 2010).

Llegados/as a este punto, se podrían acontecer cuestiones acerca de cuál fue el detonante clave para hacer despegar a una revista que no era novedosa en ilustrar fotografías eróticas (pues estas ya se venían dando desde el daguerrotipo) contextualizadas en un sistema que controlaba y censuraba toda imagen que destacase sexualmente.

Para Preciado, Hefner había utilizado nuevas técnicas que permitieron este despliegue: maquetación y color, junto con ampliar el tamaño de las fotografías convirtiéndolas en desplegable. Estas novedades le abrieron camino hacia un futuro prometedor que, a su vez, propició la reinvención de lo que hoy se conoce como pornografía convencional. 
Por otra parte, y aunque han sido varias las películas que han marcado historia en este género, es imprescindible destacar Garganta profunda (1972), uno de los metrajes más polémicos y con más alcance social, tanto para un público superficial que aplaudía la cosificación desmesurada de la actriz Linda Lovelace, como por sus declaraciones posteriores en relación con la gran cantidad de agresiones y maltratos a la que fue sometida (Marzano, 2015).

Como bien argumenta la autora, este filme fue detonante de un sinfín de materiales pornográficos, no siendo hasta los años ochenta, cuando estas películas empezaron a ser restringidas debido a su contenido no apto para menores. Es a partir de entonces cuando comenzaron a categorizarse como cine $\mathrm{X}$, abriendo las puertas a una década que le procedía, con una difusión más rápida y accesible a cualquier persona de cualquier edad.

Debido a la demanda persistente e insaciable, casi al comienzo de la nueva era, la pornografía logró multiplicar e innovar sus instrumentos de producción y reproducción, ofreciendo nuevas formas de contemplarla. Una de las innovaciones más características fue la incorporación del «Hentai», la cual consiste en presentar pornografía a través de elementos animados japoneses. Otras, en cambio, fueron la creación de nuevas categorías que ayudaban a encontrar, específicamente, el material deseado (Hidalgo, Gómez \& Vega, 2007).

Siguiendo a los/las autores/as, las categorías podían estar divididas por el grado de intensidad de las prácticas (como el fetichismo o el sadomasoquismo) o por el rango de edad. Algunos de estos ejemplos se encuentran en las categorías «Mature» (mujeres maduras) y «Teen» o «Barely legal» (actrices que, aun siendo mayores de edad, poseen un físico parecido al de una adolescente o al de una mujer de 18 años). Junto a ello, comenzaron a ofrecer pornografía a tiempo real a través de los videochats y las webcams.

Este principio, el cual rememora a los comienzos de la pornografía previamente analizados en el apartado anterior, vuelve a conseguir mediante una acción restrictiva, una reacción que tiene como resultado un empeoramiento de lo que se esperaba atajar. En este caso, tanto el acceso de menores a la pornografía, como vídeos donde descansa la cara más misógina del heteropatriarcado.

Una cuestión que puede suscitar las dudas por parte de la sociedad actual es si la industria pornográfica ha ampliado su público y perspectiva de enfoque. Según nuevos estudios, la macro industria pornográfica con una aproximación ganancial de 10.000 millones de dólares anuales destina actualmente sus materiales no solo a su público original, los hombres, si no que se ha ampliado hacia a un nuevo público, las mujeres (Anónimo, 1995; citado por VeraGamboa, 2000).

Ante este estudio es necesario recordar que la industria comprende a hombres con gran poder dentro de los sistemas económicos, políticos y de comunicación, los cuales tienen relación con miembros del crimen organizado como son: la mafia italiana, rusa, yakuza japonesa, grupos terroristas, guerrillas, secuestradores, cárteles de narcotraficantes, traficantes de armas, prostitución o turismo sexual, entre otros (Hidalgo, Gómez \& Vega, 2007). Dicho de otro modo, la pornografía se encuentra ligada intrínsecamente al poder de dominio patriarcal. 
Para mayor veracidad de la argumentación que se defiende, se ha tomado de muestra un estudio realizado por Del Barrio (2014), en base a la información recopilada en las bases de datos pornhubinsights, alexa y freewebsitereport, sobre los/las consumidores/as de la pornografía convencional que se divulga desde los dos portales principales.

A continuación, se muestran dos graficas que representan, por un lado, los vídeos ofrecidos dentro del portal Pornhub y Xvideos y por otro, las características físicas resaltadas de los/las actores y actrices.

Gráfica 1: Vídeos ofrecidos

\begin{tabular}{|c|c|c|c|}
\hline \multicolumn{2}{|c|}{$\begin{array}{r}\text { Pornhub: } \mathrm{N}^{\circ} \text { total de vídeos: } 363.064 \\
\mathrm{~N}^{\circ} \text { total de categorías: } 61\end{array}$} & \multicolumn{2}{|c|}{$\begin{array}{r}\text { Xvideos: } \mathrm{N}^{\circ} \text { total de vídeos: } 13.070 .603 \\
\mathrm{~N}^{0} \text { total de categorías: } 2.001\end{array}$} \\
\hline $\begin{array}{l}\text { Mayor cantidad de } \\
\text { vídeos }\end{array}$ & $\begin{array}{l}\text { Menor cantidad de } \\
\text { vídeos }\end{array}$ & $\begin{array}{l}\text { Mayor cantidad de } \\
\text { vídeos }\end{array}$ & $\begin{array}{l}\text { Menor cantidad de } \\
\text { vídeos }\end{array}$ \\
\hline $\begin{array}{l}\text { Pornostars } \\
(43.133)(11,9 \%) \\
\end{array}$ & $\begin{array}{l}\text { Bisexual } \\
(293)(0,1 \%) \\
\end{array}$ & $\begin{array}{l}\text { Blowjob } \\
(1.215 .838)(9,3 \%)\end{array}$ & $\begin{array}{l}\text { Spain } \\
(1.135)(0,01 \%)\end{array}$ \\
\hline $\begin{array}{l}\text { Amateurs } \\
(22.743)(6,3 \%)\end{array}$ & $\begin{array}{l}\text { Divertidos } \\
(448)(0,1 \%)\end{array}$ & $\begin{array}{l}\text { Hardcore } \\
(1.181 .243)(9 \%)\end{array}$ & $\begin{array}{l}\text { Shaving } \\
(1.231)(0,01 \%)\end{array}$ \\
\hline $\begin{array}{l}\text { Tetonas } \\
(20.810)(5,7 \%)\end{array}$ & $\begin{array}{l}\text { Con El Puño } \\
(478)(0,1 \%)\end{array}$ & $\begin{array}{l}\text { Teen } \\
(841.817)(6,4 \%)\end{array}$ & $\begin{array}{l}\text { Gay-fisting } \\
(1.263)(0,01 \%)\end{array}$ \\
\hline $\begin{array}{l}\text { Adolescentes } \\
(19.627)(5,4 \%)\end{array}$ & $\begin{array}{l}\text { Japonés } \\
(500)(0,1 \%)\end{array}$ & $\begin{array}{l}\text { Anal } \\
(534.625)(4 \%)\end{array}$ & $\begin{array}{l}\text { Paja } \\
(1.435)(0,01 \%)\end{array}$ \\
\hline $\begin{array}{l}\text { Sexo Duro } \\
(19.345)(5,3 \%)\end{array}$ & $\begin{array}{l}\text { Hombre Solo } \\
(604)(0,2 \%) \\
\end{array}$ & $\begin{array}{l}\text { Facial } \\
(366.144)(2,8 \%)\end{array}$ & $\begin{array}{l}\text { Biggirl } \\
(1.493)(0,01 \%)\end{array}$ \\
\hline $\begin{array}{l}\text { Anal } \\
(15.611)(4,3 \%)\end{array}$ & $\begin{array}{l}\text { Bukkake } \\
(618)(0,2 \%)\end{array}$ & $\begin{array}{l}\text { Boobs } \\
(348.570)(2,7 \%)\end{array}$ & $\begin{array}{l}\text { Soft } \\
(1.589)(0,01 \%)\end{array}$ \\
\hline $\begin{array}{l}\text { Mamadas } \\
(11.095)(3,1 \%)\end{array}$ & $\begin{array}{l}\text { Universitarias } \\
(629)(0,2 \%) \\
\end{array}$ & $\begin{array}{l}\text { Gangbang } \\
(171.965)(1,3 \%)\end{array}$ & $\begin{array}{l}\text { Pegging } \\
(2.133)(0,01 \%)\end{array}$ \\
\hline
\end{tabular}

Fuente: Elaboración propia extraído de Del Barrio, E. (2014), p.114

Si se comienza analizando los datos de la plataforma Pornhub, se observa que las dos categorías que engloban la mayor cantidad de vídeos son la categoría «Pornostars», con un $11,9 \%$, y la categoría «Amateurs», con un 6,3\%. Pero cabe matizar que ambas son categorías generales y antagónicas que pretenden llevar a cabo las fantasías más específicas de los/las 
usuarios/as a través de dos modos de representación: por un lado, desde una pornografía con gran producción (11,9\%), y por otro, desde la inexperiencia e informalidad (6,3\%).

Tras ello, resulta destacable que un 6,4\% en Xvideos y un 5,4\% Pornhub de las categorías «Teen»y «Adolescentes» respectivamente, se encuentren frente a un 0,2\% en la categoría «Universitaria» de Pornhub. Aquí se puede apreciar una de las fantasías descritas anteriormente por Hidalgo, Gómez \& Vega (2007), la cual lleva siendo alimentada desde sus comienzos en los años 90.

Del mismo modo, las categorías que engloban los grados más extremos de prácticas se ven reflejados a partir de la categoría «Sexo duro» con un 5,3\% (Pornhub) y «Hardcore» con un $9 \%$ (Xvideos), frente a un $0,01 \%$ en «Soft» (Xvideos).

Otro dato destacable que aporta Del Barrio (2014) es que ninguna categoría perteneciente a Pornhub, contiene la palabra «mujer», pudiéndose percibir en las categorías «Tetonas» con un 5,7\% (Pornhub), «Boobs» con un 2,7\% (Xvideos) y «Biggirl» con 0’01\% (Xvideos), donde se etiquetan a las mujeres por unos atributos exclusivamente físicos. Asimismo, tan solo en Xvideos la palabra «mujer» aparece en «Asianwomen» y «Blackwomen», según la autora.

Además, puede apreciarse que la categoría que engloba a las prácticas de sexo oral, tan solo se considera a partir de felaciones (3,1\% en Pornhub y 9,3\% en Xvideos), mientras que el sexo oral de las mujeres no aparece reflejado en ningún porcentaje.

Por otra parte, la categoría «Anal» parece ser recurrente en ambas, siendo de un 4,3\% en Pornhub y un $4 \%$ en Xvideos. Aunque en primera instancia el sexo anal puede ser ejercido tanto en una relación heterosexual como en una relación homosexual, es imprescindible destacar que las categorías no heterosexuales representan un porcentaje mínimo, siendo un 0’01\% en las categorías «Gay-fisting» (Xvideos) y «Bisexual» (Pornhub), no estando representadas, además, las categorías lésbicas u de otras identidades.

Igualmente, resulta necesario añadir que las categorías «Gangbang» con un 1,3\% en Xvideos y «Bukkake» con un 0 ' $2 \%$, implican prácticas donde se representa a una mujer que es eyaculada y/o penetrada a través de múltiples orificios por un grupo de hombres, mientras que, por el contrario, no se refleja ninguna categoría donde sean las mujeres los sujetos activos de la escena.

Gráfica 2: Características físicas resaltadas

\begin{tabular}{|c|c|c|c|c|c|c|c|}
\hline \multirow[b]{2}{*}{$\frac{0}{0}$} & Actores & \multicolumn{3}{|c|}{$0,5 \%$ musculosos } & \multicolumn{3}{|c|}{$90 \%$ pene grande } \\
\hline & Actrices & $\begin{array}{l}70 \% \\
\text { delgadas }\end{array}$ & $\begin{array}{l}80 \% \\
\text { pechos } \\
\text { grandes }\end{array}$ & $\begin{array}{l}50 \% \\
\text { labios } \\
\text { gruesos }\end{array}$ & $\begin{array}{l}30 \% \\
\text { Rubias }\end{array}$ & $\begin{array}{l}40 \% \\
\text { Castañas }\end{array}$ & $\begin{array}{l}30 \% \\
\text { morenas }\end{array}$ \\
\hline$\therefore$ : & Actores & \multicolumn{3}{|c|}{$10 \%$ musculosos } & \multicolumn{3}{|c|}{$100 \%$ pene grande } \\
\hline
\end{tabular}

N7, 2019. Página $\mid 110$ 


\begin{tabular}{|l|l|l|l|l|l|l|l|}
\hline & & $90 \%$ & $70 \%$ & $40 \%$ & $40 \%$ & $30 \%$ & $40 \%$ \\
& Actrices & delgadas & pechos & labios & Rubias & Castañas & morenas \\
\hline
\end{tabular}

Fuente: Elaboración propia extraído de Del Barrio, E. (2014), p.114

En la imagen presentada se aprecia como los atributos físicos señalados en los actores son únicamente la musculación ( $0,5 \%$ en Xvideos y $10 \%$ en Pornhub) y el pene (90\% en Xvideos y $100 \%$ en Pornhub). En cambio, no ocurre lo mismo con las actrices, ya que sus particularidades son principalmente: un cuerpo delgado $(70 \%$ en Xvideos y $90 \%$ en Pornhub), pechos grandes (80\% en Xvideos y $70 \%$ en Pornhub) y labios gruesos (50\% en Xvideos y $40 \%$ en Pornhub).

Este conjunto variado de rasgos de las mujeres permite ver como ellas son las que principalmente ocupan la pantalla mientras que, por otra parte, de ellos no se destaca ninguna característica más allá de las ya mencionadas.

Frente a una evidente polarización estadística que permite vislumbrar el problema de este fenómeno de masas, la plataforma Pornhub realizó el pasado año un estudio estadístico en el cual afirmaba que las mujeres consumen más pornografía a través de sus smartphones (Anónimo, 2017). Esta noticia, que parece indicar que actualmente las mujeres son cada vez más propensas a ver materiales pornográficos (y con ello un aumento de paridad de consumo), oculta y relega a un plano secundario el problema principal. Y es que, éste no reside en quien consume pornografía, sino hacia quien está dirigida $y$, por ende, hacia quien convierte en sujeto dominante y objeto dominado en la escena.

Por otra parte, y a raíz de la jerarquización hombre-dominante y mujer-dominada, se encuentra uno de los problemas más importantes actualmente dentro de la esfera social y política: la imitación de las prácticas expuestas en páginas X por parte de los/las consumidores/as más jóvenes.

Vera-Gamboa (2000), a través de investigaciones y estudios revisados, afirma la inexistencia de pruebas científicas que acrediten efectos perjudiciales del consumo de estos materiales. Pero si se acepta esta premisa, se aceptaría la inexistencia relacional y vinculante entre la cultura de la violación, y el acceso y consumo libre de pornografía hegemónica.

Resulta incongruente teniendo en cuenta que estos materiales esbozan un modelo de conducta que no solo ejerce un poder indiscutible en la propagación de la cultura de la violación, si no que lleva a la práctica, a través de una interpretación recreativa, violencia de género en el estado más perverso. Uno de los casos más preocupantes se ve reflejado en el caso de la Manada, siendo uno de los vídeos más buscados en páginas porno (García, 2018).

Por otra parte, y en contraposición con la idea de inconexión entre consumo y violencia, se encuentra un estudio realizado por Sánchez, Reyes, Reyes, Quero, Reyes \& Colón (2007), 
en el que se tomaron como muestra 180 hombres con edades comprendidas entre 10 y 18 años. El resultado reveló que entre 42 y 48 hombres afirmaban recurrir a estas páginas como instrumento de aprendizaje. Por lo cual, se considera inviable tanto el no aceptar la correlación entre observación e imitación a modo de método educativo, como la creciente probabilidad de admitir prácticas sexuales no consentidas como válidas y normalizadas.

Si bien es cierto, como se ha señalado anteriormente, que la pornografía es una herramienta que permite la propagación de pensamientos que conceptualizan a la mujer exclusivamente como objeto para el disfrute masculino, es necesario suscribir que no es su único fin, ya que opera también como fuente desde donde confluyen numerosos medios de consumo en constante interconexión, como son: la publicidad, la prostitución o la trata.

Szil (2007) expone que las personas que han creado su identidad sexual por medio de las prácticas sexuales expuestas en la pornografía no llegan a diferenciar la realidad sexual y la fantasía, y es por ello por lo que muchos varones viven una doble vida: una vida fantasiosa producto de la concepción aprendida por medio de la pornografía, y otra real, junto a una mujer con identidad sexual propia.

En un contexto androcéntrico, donde todo deseo masculino ha de ser concedido, existe cabida para llevar a la práctica cualquier excentricidad demandada. Es por ello por lo que la prostitución convierte la necesidad de ejecutarla, en una oportunidad para lucrarse por medio de la compra y venta de mujeres.

Algunas de las razones, no excluyentes, por las que los hombres buscan prostitutas (Månsson, 2004) son:

- Para satisfacer la fantasía de la sucia puta: una degradación de la mujer que, a su vez, exime de toda culpa moral al cliente.

- Por probar otro tipo de sexo y/u otro tipo de mujer: normalmente para buscar prácticas que no ejerce con su pareja y/o con mujeres más acorde a los cánones de feminidad y sumisión, llevando consigo nociones fuertemente antifeministas y temor a perder la supremacía masculina.

- Para llevar a cabo la fantasía de comprar sexo: usualmente chicos jóvenes que tienen ideas inducida por ideales propagados a través de la televisión o la pornografía.

- Debido a la inexistencia de ninguna otra mujer: por no tener relaciones con mujeres ya sea por timidez, discapacidad, miedo, etc., aunque se refiere a la percepción subjetiva del cliente de lo que encuentra disponible, más que a la inexistencia de posibilidad de obtener relación con otras mujeres.

\section{¿Educación sexual- afectiva?}

No resulta sorprendente la pobre implicación política para erradicar la pornografía hegemónica debido al contexto en el que se enmarca y reproduce. Lo que sí se manifiesta impactante es la estigmatización, ocultamiento y silenciamiento cultural de asuntos que conlleven la búsqueda de prácticas sexuales, junto con un conocimiento de la identidad y educación sexual que implique ir más allá de instruir sobre la importancia del uso del 
preservativo y la prevención de las Enfermedades de Transmisión Sexual. Y es que, a pesar de que múltiples organismos internacionales argumenten la importancia de la educación sexual-afectiva, en España sigue existiendo un vacío de leyes firmes que respalde en esta materia (Bejarano \& García, 2016).

Por lo tanto, la pornografía utiliza este tabú y vacío político para adquirir el único rol educador, y al ser la única fuente pedagógica, las fantasías se convierten en una realidad y/o en un deseo de llevarlo a la práctica, perpetuando un sistema que agudiza aún más la mirada inocente e inimputable hacia el hombre y el predominio de poder.

Zapiain (2000) afirma que la presencia de una formación real permitiría una mayor integración social y un mayor crecimiento personal. Además, proporcionaría mecanismos de auto gestión de los sentimientos, aceptación del cuerpo y junto a ello, aumento de la empatía, respeto por los demás y la visibilidad de orientaciones sexuales aún recriminadas. Todo ello a la vez que disminuye la educación diferencial con el fin de, entre otros objetivos, evitar discriminaciones y abusos sexuales.

Pero el problema desde un punto de vista menos conformista reside en que se tiende a hacer uso de una perspectiva dicotómica. Dicho de otra forma, deseos y maneras distintas de sentir y experimentar entre géneros normativos (mujer y hombre), y entre dos únicas orientaciones sexuales: heterosexualidad y homosexualidad.

Y es que, como bien afirma Morgade (2006), la educación sigue enfocada hacia un ámbito biológico/anatómico que toma como única perspectiva, las identidades normativas. Así pues, a pesar del deseo imparable de muchos/as expertos/as por implantar planes de estudio que den respuesta a los problemas que siguen aconteciendo, se considera necesario un nuevo cuestionamiento. Es decir, si tan solo se educa a hombres y mujeres, los/las receptores/as más jóvenes se asumirán así mismos/as en base a una anatomía física y/o a un género previamente aceptado por el sistema.

Así pues, aunque la salud sexual según la Ley Orgánica 2/10 de 3 de marzo, de Salud Sexual y Reproductiva y de la Interrupción Voluntaria del Embarazo, acoja en su definición, el bienestar sexual, independientemente de la identidad sexual de la persona; en materia de educación, la visibilidad de colectivos no normativos se presenta carente.

Es por ello por lo que, antes de emprender una puesta en marcha de gran calibre y peso educativo, se muestra necesario cuestionar y rescribir parte del discurso litúrgico para evitar una educación que favorezca exclusivamente la reproducción de identidades y cuerpos no patologizados y aceptados por el sistema.

\section{Conclusiones}

La pornografía se establece como uno de los medios de control sobre las sexualidades más importantes actualmente. Un mecanismo legitimado que ejerce tanto la medicina, como los poderes políticos y económicos en un sistema de libre mercado. 
Además, la politización de los cuerpos se encuentra presente dentro del sistema y, con ello, las diferencias en base a la anatomía sexual y de género que sufren las mujeres por el hecho de serlo. Este poder, patriarcal y capitalista, convierte la discriminación de género en un escaparate de cosificación de la mujer y perpetuación de la violencia de género. Debido a la ausencia de los medios pedagógicos sobre las sexualidades, identidades y usos del placer, la pornografía hegemónica se convierte en el recurso más empleado para la propagación de comportamientos estereotipados y patriarcales.

Finalmente, se considera que las propuestas para una educación sexual-afectiva real deben ir encaminadas, por una parte, a la disminución, erradicación de la violencia de género y prácticas discriminatorias; y por otra, hacía una educación que abarque también a identidades no normativas.

Si estas acciones se dirigen exclusivamente hacía identidades convencionalmente aceptadas, mermaría uno de los objetivos principales de la educación inclusiva. Lo cual permitiría al sistema seguir modificando, reproduciendo y reduciendo los cuerpos y las identidades diversas hacia dos identidades dicotómicas y normativas.

\section{Referencias}

Anónimo. (2017, 20 de abril). ¿Hombres o mujeres? Estudio revela quiénes ven más porno. La República. Recuperado de https://bit.ly/2Ni07Zj

Anónimo. (1995). Pornografía para mujeres. En: Secretos de la pareja. Barcelona: Planeta Agostini, pp. 1700-2.

Anónimo. (2018, 8 de marzo). Marchas feministas masivas desbordan las calles en un 8M para la historia. eldiario.es. Recuperado de: https://bit.ly/2OAkT35

Barzani, C. A. (2015). Introducción. En Barzani, C. A. (Copilador), Actualidad de Erotismo y Pornografía (pp.8-14). Ciudad Autónoma de Buenos Aires: Topía.

Becerra, J. M. (1989). Algunos dobletes semánticos en el español hablado actual. Revista española de lingüística aplicada, (5), 23-35.

Bejarano, M., \& García, B. (2016). La educación afectivo-sexual en España. Análisis de las leyes educativas en el periodo 1990-2016. Opción, 32 (13), 756-789.

Cabrera, E. (2013, 13 de enero). España ignora la educación sexual. eldiario.es. Recuperado de https://bit.ly/2PMguKy

Castells, M. (2009). Comunicación y poder. Madrid: Alianza.

Del Barrio, E. (2014). Pornografía y educación sexual: ¿libertad de expresión? o ¿prisión de géneros? Análisis de la pornografía mainstreaming. En Suárez, J.C., Lacalle, R., \& 
Pérez, J. M. (Eds.), Libro de Actas del II Congreso Internacional de Comunicación y Género (pp.108-119). Sevilla: Dykinson.

Figari, C. E. (2008). Placeres a la carta: consumo de pornografía y constitución de géneros. La ventana. Revista de estudios de género, 3(27), 170-204.

García, C. (2018, 8 de mayo). ¿Prohibimos el porno? 20minutos. Recuperado de https://bit.ly/2POi7r7

Hidalgo, J. A., Gómez, D., \& Vega, D. (2007). La otra mirada: El impacto social de la oscura, interactiva, violenta, poderosa y multimediatica industria de la pornografía. Las claves necesarias de una comunicación para la democracia. XIX Encuentro nacional de la AMIC. Recuperado de http://cort.as/-AKFT

Hunt, L. (1993). The Invention of Pornography: Obscenity and the Origins of Modernity, 1500-1800. New York: Zone Books.

Koning, F. (1978). Historia de la pornografía. Barcelona: Bruguera.

Leite, J. (2012). Labirintos conceituais científicos, nativos e mercadológicos: pornografía com pessoas que transitam entre os gêneros, Cadernos Pagu, (38), 99-128.

Llorente, M. E. (2013). Erotismo y pornografía: revisión de enfoques y aproximaciones al concepto de erotismo y de literatura erótica. Anuario de Letras. Lingüística y Filología, 40, 359-375.

Månsson, S. A. (2004). Men’s practices in prostitution and their implications for social work. Social work in Cuba and Sweden: Achievements and prospects.

Marzano, M. (2015). La paradoja de la pornografía contemporánea entre la libertad, goce y estereotipos de sumisión. En Barzani, C. A. (Copilador), Actualidad de Erotismo y Pornografía (pp.8-14). Ciudad Autónoma de Buenos Aires: Topía.

Montgomery, H. (1973). Historia de la pornografía. Buenos Aires: La Pléyade

Morgade, G. (2006). Sexualidad y prevención: discursos sexistas y heteronormativos en la escuela media. Revista del Instituto de Investigaciones en Ciencias de la Educación, 24, 27-33.

Orozco, G., Navarro, E., \& García-Matilla, A. (2012). Desafíos educativos en tiempos de auto-comunicación masiva: la interlocución de las audiencias. Comunicar, 19(38), $67-74$.

Prada, N. (2010). ¿Qué decimos las feministas sobre la pornografía? Los orígenes de un debate. La manzana de la discordia, 5(1), 7-26. 
Preciado, B. (2010). Pornotopía: Arquitectura y sexualidad en "Playboy" durante la guerra fría. Barcelona: Anagrama.

Sánchez, N. P., Reyes, U., Reyes, D., Quero, A., Reyes, U., \& Colón, F. (2007). Entorno de la Consulta de Pornografía y su Repercusión en Relación a la Sexualidad en un Grupo de Adolescentes Masculinos. Boletín Clínico Hospital Infantil del Estado de Sonora, 24(1), 3-8.

Szil, P. (2007): Los hombres, la pornografía y la prostitución. Ponencia presentada al Congreso de los Diputados de España, en BOE, 379, pp. 84-89.

Tello, A. (1992). Gran diccionario erótico de voces de España e Hispanoamérica. Madrid: Temas de Hoy.

Vera-Gamboa, L. (2000). La pornografía y sus efectos: ¿Es nociva la pornografía? Revista Biomédica, 11(1), 77-79.

Zapiain, J. (2000). Educación afectivo sexual. Anuario de sexología, 6, 41-56. 